sensitivity of photographic materials was also described. Examples were given of how instruments incorporating the above principles are used for environmental control and for personal monitoring.

The conference came to an end after a paper by Dr. T. E. Graham, of the Windscale works of the U.K. Atomic Energy Authority, on "Diagnostic Aids in Radiation Medicine". He said that the doctor's reliance on instruments is perhaps greater in radiation work than in any other occupational field. His clinical examination reveals almost nothing unless the case is an extreme one. Radiation-induced disease has such a long latent period before it becomes clinically detectable that an early assessment of exposure is of paramount importance in prognosis. The reassurance value of negative findings is of no less importance. Techniques were described for the assessment of radiation dosage both during the exposure and after it. Radioactive contamination of the skin and problems connected with contaminated wounds were also discussed. Internal contamination and the absorption of radioactive substances present the most serious diagnostic difficulties. Here the doctor is confronted with a symptomless patient, whose history might be quite unhelpful, with perhaps only a single fact-a positive urine analysis result, for example - to guide him. Radiochemical techniques, with all their inherent uncertainty, then become the main diagnostic aids. Descriptions were given of some remarkable instruments which perform quantitative analysis of the most complex mixtures of isotopes, often present in the minutest amounts in the body and its excreta.

A full report of the conference will appear in the June issue of Instrument Practice. Copies can be obtained from the scientific secretary of the Society, Dr. D. J. Turner, Medical Research Council Laborabories, Holly Hill, Hampstead, N.W.3.

\section{N. Davirs}

\section{PHYSICS TRAINING IN SCOTLAND}

$\mathrm{T}$ HE Scottish Branch of the Institute of Physics and the Education Group joined in conference at the Royal College of Science and Technology, Glasgow, on April 12 and 13. From the first it was clear that the main concern of the conference was the proper education of the future physicist, rather than simply 'training' in physics, as stated on the programme; and, once the slight but significant differences in terminology due to the Border were understood, there was a good measure of cordial agreement between both the suppliers and demanders of physicists as to the kinds of education desired.

In his opening address, Prof. W. H. J. Childs (Heriot-Watt College, Edinburgh) said that ineffective panic measures in the future could only be forestalled by facing the fact that the shortage of trained scientific workers would be permanent, and by planning ahead in these terms. Increase in the numbers of real scientists of university calibre was unlikely, and the problem is to develop the abilities of less gifted people. He suggested for consideration a reduction in the content of undergraduate courses, and the deferment of specialized instruction to the postgraduate stage; while, at the other end, steps should be taken in the first year to fill the gaps in the knowledge supposedly acquired at school. These points were, in fact, dealt with by several speakers.

Mr. M. Milburn (Metals Division, Imperial Chemical Industries, Ltd.) spoke of the graduate physioist in industry. Versatility and an ability to apply fundamental physics logically to different types of problem were needed. Industry could provide its own specialist training; a basic understanding of physics, and some fluency in writing reports, were the qualities it sought in recruits. The needs of the Scientific Civil Service were voiced by Dr. R. A. Smith (Royal Radar Establishment, Malvern), who said that the university graduate required further trainingnot merely specialized training, but a postgraduate course in fundamental physics. This also was one of the points made by Mr. J. R. Atkinson (University of Glasgow), who advocated first-degree courses in pure and applied physics as university studies, with the technical colleges giving advanced postgraduate training for higher degrees, including the Ph.D. It seemed, from the discussion that centred around the role of the technical colleges, that the proud tradition of undergraduate teaching there would not willingly be exchanged for the status of a solely postgraduate school. Another of Mr. Atkinson's points-the recognition that people enter the university from school at various stages of preparedness, and the steps taken to deal with this in the first-year courses at Glasgow - raised the question of the desirability of extending university courses by a preliminary year for everyone. Prof. H. Lipson (Manchester College of Science and Technology) described the course at Manchester leading to the degree of B.Sc.Tech. Essentially, this is a course in fundamental physics, with a leaning towards engineering provided by one term's courses in engineering drawing and in workshop practice. Great importance is attachod to training in essay writing. The final examination is not exclusively on matter covered by lectures, and includes a general paper on physics, and an English essay paper. To avoid overloading the students, a good deal of the more specialized theoretical work of the usual kind of undergraduate course, such as relativity and wave mechanics, is omitted.

As a relief from the day's preoccupation with purely intellectual development, the talk in the evening by Prof. Hugh Nicol (West of Scotland Agricultural College) gave much thought for food. A new factor in the world's economy had intervened at the turn of the century by the injection into the hitherto self-supporting nitrogen cycle of artificial fertilizers which needed fuel and power for their production. Food is now being grown by drawing on irreplaceable mineral resources, and though at present food-fuel consumption is only a small fraction of the whole, the way in which the use of fuel for non-food purposes makes inroads into this dwindling capital during the next fow decades may be decisive later.

At the second session, Mr. A. L. Chilcot (Ferranti, Ltd., Edinburgh) described the schemes for the training of technicians. Student apprenticeship schemes undertaken by industry in conjunction with education authorities recruited people with 'higher science' and 'lower mathematics' in the Scottish Leaving Certificate, and carried training on to the level of the Higher National Certificate. Dr. G. Morris (Imperial Chemical Industries, Ltd., Stevens- 
ton), the Institute of Physics assessor in Scotland for national certificates, spoke of the operation of the scheme in Scotland. Those present with some experience of assessing in these examinations may have felt that Dr. Morris possibly over-estimated their academic level as it stands at present, but endorsed his tribute to the quality and perseverance of the candidates who complete the arduous course successfully.

For the benefit of the English teachers present, Mr. J. C. Young (Paisley Academy) had to do some preliminary explanation of the Scottish school system, before giving his talk on the teacher's point of view. He spoke of the untapped resources of the junior secondary schools (the Scottish counterparts of the English secondary modern schools), and urged industrialists to take boys from these schools, and help them during their student apprenticeship days with special encouragement and guidance. Mr. D. McGill (Glasgow Academy) compared the place occupied by physics in the Scottish Leaving Certificate courses, and in the General Certificate of Education syllabuses. The Scottish system, he felt, gave a breadth and depth missing from the English system, but stopped a year too soon; the English system, in spite of its tendency to premature specialization, enabled the boy to develop generally during his last year in the sixth form. An extra year at school, with entry into the second year of the Scottish university course, would give the best of both dispensations. Finally, Mr. W. S. Gray (Scottish Education Department) spoke of recent and impending changes in the status of physics in the Scottish Lesving Certificate examination. These, ultimately giving an ordinary level examination comparable in standard with the General Certificate of Education at ordinary level, and taken at the same stage in the school career, with the upgrading of physics to a full subject, should improve the equipment with which the young apprentice begins his career, and also offer something comparable with the deeply entrenched traditional Latin to challenge (and thus attract) the ablest boys.

G. R. NOAKES

\section{SALARIES OF GRADUATES IN INDUSTRY}

$\mathrm{F}^{\mathrm{o}}$ LLOWING its sample survey of graduate employment published last autumn, Political and Economic Planning has now issued a more detailed analysis* of salaries received by university men employed in industry which also examines them in relation to the graduate's faculty of study. Starting salaries of graduates who entered industry in 1950-51 were not very different from those paid to graduates as a whole, but industrial salaries four years after graduating were considerably higher than those elsewhere. Science graduates started at higher salaries than arts graduates or technologists. At the time of the survey (autumn 1954) there was little difference between the level of salaries paid to men who remained with their first industrial employer, although the scientists among them were slightly in the lead: arts graduates did considerably better than the others among those who changed their jobs, and, on average, were doing best among the Planning, Vol. 23, No. 408 : Salaries of Graduates in Industry.
Pp. graduates as a whole by 1954 , though the difference ( $£ 767$ compared with $£ 736$ ) is too slight to form a basis for firm conclusions. Scientists had then lost their initial lead of $\mathfrak{f 7 0}$, but the arts men were also rather older then the scientists. Men in the oldest age-group (aged 26 or more on graduating) had increased their $£ 20$ lead to $£ 45$ at the time of the survey, and men with a first-class degree, starting with about $£ 100$ more than those with a second- or with a third-class or 'other' degree, maintained a large differential.

No correlation of significance was found between the size of the establishment and the salary-level. Mining and quarrying, oil, and chemicals and allied trades paid higher salaries, and the public utilities lower salaries at both stages, consumer goods industries paying average starting but high subsequent salaries. Industries varied most in the salaries paid to technologists : in industries in which high salaries were received, technologists started with more than arts graduates; in industries at the other end of the range they started with less, but a comparable analysis could not be made in autumn 1954, since the number of graduates in most product groups was too small. In the consumer-goods industries and the chemical and allied trades, arts graduates, and also scientists, were then receiving relatively high salaries, while in electrical engineering technologists were by then receiving rather more than scientists.

From this slender evidence Political and Economic Planning draws the conclusion that industry was not failing through its salary policy to make itself attractive to graduates. It was attracting into its ranks two-thirds of the technologists, nearly twofifths of the scientists, and one-eighth of the arts men and a comparable proportion of men with a first-class honours degree. There is no single answer to the question whether, with some 27 per cent of the output of graduates, industry was attracting too high or too low a proportion of such men : the proportion was too low for industry, but too high from the point of view of other competitors for graduate scientists and technologists and the best type of arts men. It is not easy to tell whether the teaching profession and the Civil Service are now in a relatively stronger position as a result of recent increases in the salaries they offer. The second main conclusion drawn in the broadsheet, that the greatest advances in salary in this period were not going to the scientists and technologists, does not support any sweeping deductions. The figures relate to only one year of graduates and a mere four years of post-university employment at the outset of a career, and it would be rash to infer that the better scientists and technologists are not being brought into the management succession as frequently as the better arts men. The broadsheet seems to imply that the present salary policy offers little advantage to scientists and no advantage to technologists over arts men at the start of their career, and results in the promotion of some of the arts men to positions carrying higher salaries than those filled by any of the scientists or technologists. Even if the differential were more substantial it would be hard to assert that the policy discourages men from reading science or technology rather than arts subjects. There were too many other factors in the past encouraging the ablest schoolleavers to read arts, and the figures could imply no more than that industry has found the ablest minds among such graduates. 